\title{
RITOS E VIOLÊNCIA NO ENSINO FUNDAMENTAL
}

\author{
RITES AND VIOLENCE IN ELEMENTARY EDUCATION
}

\author{
RITOS Y VIOLENCIA EN LA ENSEÑANZA BÁSICA
}

Jose Bispo Miranda*

\begin{abstract}
Resumo: O artigo visa explicar o surgimento de comportamentos violentos na escola a partir dos atos aparentemente insignificantes condicionados e gerados pelo mito, pelo ritual e pelo rito. A compreensão da violência tem se dado por fatores econômicos, sociais, culturais e pedagógicos; contudo, a proposição deste trabalho modifica esse eixo: os comportamentos dos indivíduos podem ser condicionados por mitos, rituais e ritos da sociedade envolvente. No campo empírico, os trabalhos de coleta de dados (observação e documentação) foram realizados numa escola municipal; os sujeitos foram crianças e professores do $1^{\mathrm{a}}$ ao $5^{\mathrm{o}}$ ano do Ensino Fundamental. A análise dos dados ocorreu com base no referencial da antropologia (Campbell, Eliade e Segalen) e pela teorização progressiva. Conclui-se que a percepção de atos sociais condicionados pela lógica ritual da sociedade envolvente pode produzir olhares pedagógicos sobre as crianças nas primeiras séries na Educação Básica e identificá-los como produtores e reprodutores de atos que podem implicar em violência na escola e, dessa forma, intervir de forma propositiva junto à comunidade escolar.
\end{abstract}

Palavras-chave: Rito. Escola. Ensino Fundamental. Violência na escola.

\begin{abstract}
This article aims to explain the emergence of violent behavior in schools from the seemingly insignificant acts conditioned and generated by the myth, the ritual and the rite. The understanding of violence has been understood through economic, social, cultural and educational factors, however, the purpose of this paper modifies that: the behavior of the beings can be conditioned by myths, rituals and rites of the surrounding society. The trajectory of this empirical-analytic research has as reference the ideas of Campbell, Eliade and Segalen. On the empirical side, the work of data collection (observation and documentation) was conducted in a public school, with children and teachers from the 1st to the 5th year of Elementary Education. The data analysis was based on the anthropological framework (Campbell, Eliade and Segalen) and progressive theorizing. We conclude that the perception of social acts conditioned by the logic of ritual surrounding society can produce pedagogical eyes on children in the first grades in Basic Education and identify them as producers and reproducers of acts that can result in violence at school and thus intervene propositionally with the school community.
\end{abstract}

Keywords: Rite. School. Elementary Education. Violence at school.

*Universidade Estadual do Piauí - UESPI - professorjosebispo@hotmail.com 
Resumen: El artículo visa explicar el surgimiento de comportamientos violentos en la escuela a partir de los actos aparentemente insignificantes condicionados y generados por el mito, por el ritual y por el rito. La comprehensión de la violencia se dio por factores económicos, sociales, culturales y pedagógicos; sin embargo, la proposición de este trabajo modifica ese eje: los comportamientos de los individuos pueden ser condicionados por mitos, rituales y ritos de la sociedad involucrada. La trayectoria de esta investigación analítico-empírica. En el campo empírico, los trabajos de coleta de dados (observación y documentación) fueron realizados en una escuela municipal; los sujetos fueron niños y profesores del $1^{\mathrm{a}}$ al $5^{\circ}$ año de la Enseñanza Básica. Los análisis de los dados ocurrieron con base en el referencial de la antropología (Campbell, Eliade e Segalen) y por la teorización progresiva. Se concluye que la percepción de actos sociales condicionados por la lógica ritual de la sociedad involucrada puede que produzca vistazos pedagógicos sobre los niños en las primeras series en la Educación Básica y les identifiquen como productores y reproductores de actos que puedan implicar en violencia en la escuela y, de esa forma, intervenir de forma propositiva junto a la comunidad escolar.

Palabras-clave: Rito. Escuela. Enseñanza Básica. Violencia en la escuela

\section{Introdução}

Este artigo pretende debater a violência na escola a partir de um olhar diferenciado dos trabalhos acadêmicos sobre o tema. As luzes desta escolha recaem sobre os ritos e na tentativa de entender através deles a manifestação primeira de atos que podem vir a produzir atos de violência na escola e na trajetória social das crianças.

Parte-se da hipótese de que, na comunidade escolar, são criados e produzidos atos individuais e sociais que estão vinculados a uma perspectiva social, mesmo que as crianças ainda não tenham consciência dela, e a não percepção por parte da escola da existência desses atos impede o controle mais efetivo do destino social dos infanto-juvenis.

Para Bourdieu (1996), as ações humanas em sua maioria não têm como base a intenção, mas são produzidas a partir de disposições adquiridas, sem que a pessoa tenha a consciência do verdadeiro objetivo dessa ação na estrutura social.

Este artigo foi produzido por meio de uma investigação que verificou nas práticas escolares a manifestação de ritos e sua relação na convivência escolar para possibilitar o melhor conhecimento do cotidiano da escola e encontrar as implicações daquelas manifestações nos conflitos, nas competições e no medo entre alunos e professores nas primeiras séries $\left(1^{\circ}\right.$ ao $5^{\circ}$ ano).

O percurso da pesquisa levou-nos a alcançar três objetivos: 1) verificar o cotidiano da escola através da observação; 2) identificar os ritos e sua relação com a convivência escolar; 3) perceber o papel de docentes, dos gestores e dos alunos no reforço ou não aos ritos escolares.

O estudo bibliográfico foi realizado em textos focados em como se fazer uma pesquisa etnográfica, executar a técnica da observação e em estudos sobre mitos, rituais e ritos contemporâneos. As atividades de campo foram realizadas por meio de observação 
direta, visita e contato com gestores, professores, alunos e servidores na escola.

A escolha da Escola Canto Feliz (nome fictício) ocorreu devido à sua localização, na zona norte de Teresina, especialmente numa região pobre, com grande número de crianças e com famílias compostas geralmente pela mãe e os filhos (as). O entorno da escola, além de estar situado no conjunto habitacional, conta com um hospital e uma creche municipais, uma avenida duplicada que corta o bairro no sentido oeste/leste. O fato de já trabalharmos com a referida escola em outra pesquisa anterior e a boa recepção de gestores, professores, alunos (as) e servidores contribuíram para esta decisão.

Esta unidade de ensino atende crianças e jovens do Ensino Fundamental $\left(1^{\circ}\right.$ a $9^{\circ}$ ano, sendo que no turno da noite funciona o Ensino Médio). Esta pesquisa estudou os ritos entre os (as) alunos (as) do $1^{\circ}$ ao $5^{\circ}$ ano.

A localização da escola, a distância da moradia dos professores e o tempo de chegada dos docentes para as aulas no turno da manhã fizeram com que o horário da entrada dos (as) alunos (as) fosse mudado e adaptado para as $08 \mathrm{~h}$.

A investigação foi realizada no período de setembro de 2009 a outubro de 2010.

O interesse para o estudo dos ritos, especialmente os existentes na escola, surgiu após a conclusão de pesquisas com a temática referente à violência na escola. Inicialmente, verificou-se que os comportamentos considerados violentos no interior da escola possuem "raízes" dentro e fora da escola, mas suas ramificações estavam além do tempo. A noção de tempo compreende a historicidade, porém deve alcançar os primórdios de estruturação da cultura. Para isso a noção de "ritual" é essencial na percepção de práticas sociais organizadas, uma vez que o ritual é associado ao mito e, consequentemente, às formas primeiras da sociedade humana.

Neste trabalho, a verificação de ritos escolares possui a finalidade de observar que as causas da violência, além de serem múltiplas, podem estar num tempo anterior ao da civilização moderna. O estudo e a descoberta desses ritos trazem à tona a existência do mito nas sociedades modernas, o que pode ser verificado no estudo de suas manifestações e características dos fenômenos coletivos e/ ou práticas que exijam o reconhecimento e a legitimidade individual e coletiva, o caso dos transes, dos casamentos, dos trotes, das curas individuais e coletivas, da unidade prometeicas e outros.

A produção deste artigo foi um desafio, primeiro porque o estudo sobre os ritos não é frequente na Academia, mesmo na Antropologia; segundo pelo conteúdo; a leitura sobre os ritos está numa literatura pouco utilizada nos trabalhos mais recentes do grupo de pesquisa que participamos e pela análise das observações, das descrições, dos documentos e da bibliografia sobre a temática.

O "fazer" a atividade da pesquisa sofreu algumas adaptações, dentre elas a disponibilidade de tempo para visitas à escola para contato entre alunos, professores, servidores e gestores, ou seja, foi necessária a realização de maior número de observações diretas, demandando a dificuldade de maior envolvimento de bolsistas para a pesquisa. Contudo, o fascínio pela existência dos ritos e sua correlação com a cultura fincavam nossas preocupações no alcance dos objetivos propostos.

Este artigo estrutura-se com: 1) introdução; 2) a exposição da teoria que fundamenta os estudos sobre mitos, rituais e os ritos; 3) a descrição da persistência do passado no presente a partir do inconsciente; 4) interpretações das narrativas realizadas pelos observadores na escola; 5) as considerações 
finais que apontam para a existência dos mitos, rituais e ritos na sociedade e na escola e suas relações nas convivências escolares e implicações com os conflitos, com as competições e com o medo entre alunos, professores, servidores e gestores.

\section{Rito, ritual e mito: implicações.}

As noções sobre ritos, rituais e mito na bibliografia acadêmica geram confusão ao não distinguir estes conceitos, especialmente os dois primeiros. Para a investigação o conceito de mito é relevante devido à sua conexão com rituais e, consequentemente, com ritos.

Para Gomes (2009, p.147) um rito é

[...] composto de um conjunto de comportamentos padronizados, com começo, meio e fim. Esses comportamentos se diferenciam do comportamento corriqueiro, embora este também possa ser visto como padronizado, por fazer parte de uma rotina, de uma repetição de mesmos comportamentos.

O texto acima destaca a forma peculiar de identificar o rito na sociedade, contudo ainda possui dados insuficientes para nos dizer sobre o que é o rito. Van Gennep (1978) esclarece melhor ao afirmar que o rito se divide em três momentos: a separação, a liminaridade e a agregação (reincorporação). O casamento pode ser um exemplo didático de como esses momentos se apresentam no cotidiano. A separação é identificada pelo namoro, nesta fase os dois se separam do mundo dos solteiros, pois, mesmo continuando na mesma condição, escolheram alguém para beijar, trocar carícias, serem cúmplices e fazer projetos. A liminaridade é o noivado, em que os dois saem do mundo dos solteiros e, ao mesmo tempo, não entram no mundo dos casados.
Esta fase é a mais perigosa, uma vez que sem status os noivos parecem "pairar" sobre uma realidade de instabilidade e insegurança. A fase da agregação é o casamento propriamente dito, no qual os noivos ganham um novo status, o de casados. Portanto, rito são atos formalizados, expressivos e portadores de uma dimensão simbólica.

O que vem a ser ritual? Ritus significa ordem prescrita, são regras de conduta que prescrevem como o homem deve se comportar em relação às coisas sagradas (SEGALEN, 2002, p. 21). Este conceito vincula-se ao conjunto de valores da sociedade, uma vez que a estrutura social se organiza a partir das lutas e experiências (cívicas e religiosas) reafirmadas pelo “inconsciente coletivo”. A noção de ritus transcende ao de cultura, sendo aquele uma prescrição de tempos primórdios para sociedade presente. É o ritual que define como o rito será praticado. O casamento é um rito em diversas sociedades, mas a forma em que é praticado pode ser distinta, pois depende dos valores rituais daquela sociedade.

Satisfeita a correlação entre rito e ritual, se faz necessário entender as implicações destes conceitos com o conceito de mito. Com esse objetivo Eliade (1994) afirma que em sociedades arcaicas e tradicionais “[...] os mitos ainda estão vivos, onde fundamentam e justificam todo comportamento e toda atividade do homem” (p. 10). A citação aponta para as funções do mito, uma vez que a sociedade moderna o vivifica a cada momento. São os Entes Sobrenaturais (personagens dos mitos) com suas intervenções que torna o Homem aquilo que ele é hoje, um ser mortal, sexuado e cultural.

O relevante é destacar como o mito tem conexão com o rito e o ritual. Para tanto, optou-se por definir mito como sendo “[...] uma história sagrada que relata um acontecimento ocorrido no tempo primordial, o tempo 
fabuloso do princípio” (ELIADE, 1994, p. 11). Essa história está no inconsciente humano e uma vez reivindicada vem à tona para justificar e legitimar a ordem social, como diz Campbell (1992, p. 16): “O homem, parece, não se sustenta no universo sem a crença em algum pacto com a herança geral do mito”. Os mitos, no dizer de Campbell (1990, p.06), "São pistas para as potencialidades espirituais da vida humana”. Quando são reivindicados pelos homens, esses buscam sentido para vida, "uma experiência de estar vivo".

Nesta busca por uma "experiência de estar vivo” é que a sociedade moderna demonstra ser fragilizada; uma que ela não consegue universalizar a experiência dos mitos, ou a forma de organizar a sociedade se modificou o suficiente para deslocar os mitos, tornando-os ineficazes. Por outro lado, é inegável a permanência deles na sociedade, pois são visíveis empiricamente, basta retratar o mito da destinação e do tempo primordial.

Com os mitos vivificados, eles podem condicionar os valores presentes nos rituais, que por sua vez formatam os ritos nas diferentes sociedades.

Os mitos, apesar de serem locais, são universais; por sua vez, os rituais têm sua sustentação, sua fonte de valores, das crenças e dos princípios no tempo dos primórdios (característica dos mitos), contudo a estruturação dos rituais sofre variação a partir da sociedade em que são gerados, o que produz sua diversidade. Na ponta desse processo, os ritos são formatados no interior de um ritual (neste contexto este conceito está mais próximo de cultura). Para exemplificar pode-se afirmar que o casamento numa determinada sociedade segue o ritual estabelecido naquele contexto, ou seja, os valores, as crenças e os princípios daquela sociedade vão formatar o começo, meio e fim desse rito.
A percepção dessas relações torna importante o desvelamento da trajetória do tempo presente a partir dos mitos presentes no inconsciente social.

\section{A consciência do presente no inconsciente do passado}

O passado torna-se presente não apenas pelas semelhanças biológicas e químicas existentes no corpo que podem comprovar cronologicamente nossa participação na terra, mas também porque os seres sociais projetam para o futuro construções simbólicas e imaginárias do seu tempo, as quais, uma vez recuperadas (trazidas à consciência) estruturam, ordenam a vida presente. As experiências de nossos antepassados criaram uma espécie de reservatório denominado de "inconsciente", que traz à tona modelos de comportamentos sociais que podem conter: o ordinário, a transgressão, a rebeldia, a promessa, a emancipação, a subserviência e outros.

A ideia de "inconsciente" aparece neste texto com a intenção de demonstrar sua conexão com os ritos, uma vez que a imaginação e a coreografia destes remetem à lembrança de um tempo primordial, muitas vezes, guardado naquele reservatório.

Os humanos nascem predispostos à socialização, já que, sem ela, as crianças viveriam como os outros animais, mesmo com as contribuições importantes de seus antepassados. Neste sentido, o processo de inserção da criança no mundo inicia-se na família, na comunidade, na escola e na sociedade em geral. Interessa-nos apontar a existência dos ritos na escola e quais as suas influências para a convivência escolar como parte da socialização humana.

Pode parecer estranho estudar ritos na escola. Os ritos são expressões do 
comportamento coletivo de uma determinada cultura, fazendo parte do imaginário coletivo, da identidade cultural, como diz Segalen (2002), são referências culturais da sociedade.

Ritos envolvem consciência e promovem consciência; mas, como tudo que se refere à consciência, dependem da memória e contribuem para a memória. Por isso, pensando nos ritos [...] não existem histórias encerradas, rigorosamente falando tampouco haveria ritos mortos, apenas ritos esquecidos, adormecidos numa espécie de animação suspensa, que a qualquer momento podem tornar a florescer no solo das referências culturais da sociedade (SEGALEN, 2002, p. 11).

A comunidade vive o ritual sem ter percepção dos seus verdadeiros objetivos, mas o movimento desse fenômeno faz fluir práticas de sociabilidade, de coesão entre os indivíduos e grupos e/ou de disrupção social. É evidente que os grupos que partilham laços e práticas de sociabilidades modernos não reproduzem os ritos como as sociedades primordiais, mas as suas características permanecem assim como as suas funções básicas: manter a coletividade, a plasticidade e polissemia.

Neste contexto, o trabalho pretende, além de verificar a existência dos ritos no âmbito escolar, identificar a conexão dessas práticas coletivas, geralmente expressas por comportamento individual, com o conflito, a competição e o medo.

Tendo em vista o poder de um comportamento ritual expresso individualmente e/ ou socialmente, o trabalho preocupa-se com a deterioração das relações sociais nas sociedades modernas, especialmente naquelas onde o individualismo possui maior força, revelando que as instituições modernas estão fragilizadas na organização e ordenação coletivas. Para essas instituições os ritos podem ter papel fundamental na reestruturação da ordem.

Por fim, qual o campo de conhecimento capaz de apontar diretrizes teóricas para o estudo e análise dos fenômenos rituais e dos ritos? A resposta a essa questão exige uma pequena digressão.

Antropologia trabalha com objetos e sujeitos antimodernos, por isso continua a dar bases para o estudo de objetos que não pertencem à modernidade ou são produtos de sua expansão. A característica básica da Antropologia é estudo da cultura, da diferenciação, da diversidade, do Homem.

A Antropologia, pelo seu olhar, tem ampliado seu objeto de estudo: se para Franz Boas (2004, p. 326) “[...] a antropologia é a ciência que procura reconstruir a história antiga da humanidade e tenta, na medida do possível, expressar na forma de leis os modos sempre recorrentes de acontecimentos históricos”, para Laplantine (1999, p. 20) “A antropologia não é apenas o estudo de tudo que compõe uma sociedade. Ela é o estudo de todas as sociedades humanas (a nossa inclusive), ou seja, das culturas da humanidade como um todo em suas diversidades históricas e geográficas”. Já para Geertz (2001, p. 07) a Antropologia sofre de ansiedade e é

[...] decorrente da combinação de uma difusa e confusa identidade acadêmica com a ambição de relacionar tudo a praticamente tudo, para assim chegar ao fundo das coisas \{e como consequência disto\} deixa-as insegura \{falando também da filosofia\} quanto ao que cada uma deve fazer (os termos entre colchetes são acréscimos nossos).

A Antropologia consolidou não apenas o “domínio” sobre seu tradicional objeto, as sociedades tradicionais, mas o ampliou com a mudança na forma de "olhar" e perceber o 
mundo pela pluralidade, pela diferença e pela diversidade. Não é de espantar a preocupação de Geertz (2001) com a aparente insegurança da Antropologia em razão do muito que tem por fazer.

No que diz respeito ao campo da Antropologia, de seus limites e potencialidades, este trabalho utiliza-se de sua vasta tradição no estudo dos mitos, rituais e ritos e de suas implicações na vida moderna, especialmente de sua metodologia.

\section{Percursos e descaminhos na busca da compreensão do presente pelos ritos}

Na maioria de nossas análises encontramos o elo explicativo no entorno das implicações com a sociedade capitalista, a desagregação familiar, as políticas públicas, a gestão escolar, a formação de professores, o comportamento infanto-juvenil, dentre outras. Neste trabalho observou-se a vinculação do comportamento infanto-juvenil na escola com a existência de ritos, ou seja, como determinadas práticas sociais ou conjunto de atividades organizadas e institucionalizadas, no qual as pessoas se expressam por meio de gestos, símbolos, linguagem e comportamento, transmitem um sentido coerente ao ritual (OTTO, 2006).

Compreende-se enquanto atividade institucional aquela na qual as ações tornam-se rotineiras e resultam em normas e regras sociais. As atividades devem ser coerentes no interior de um conjunto de ações relacionadas. $\mathrm{O}$ rito se constitui como um conjunto de atos formalizados, expressivos, portadores de uma dimensão simbólica e, por assim entendê-lo, a trajetória desta pesquisa deve atravessar a técnica da observação. O que é a observação? Ela é quase autoexplicativa, observa, escuta e registra (SILVERMAN, 2009). Não é por acaso que ela está inclusa na etnografia. Mas o que vem a ser etnografia? Segundo Delamont (apud SILVERMAN, 2009, p. 71), "Etnografia é o estudo das pessoas em locais ou 'campo' que ocorrem naturalmente, através de métodos de coleta de dados que captam seus significados sociais e suas atividades comuns $[. .]$.$” .$

No texto "O trabalho do antropólogo: olhar, ouvir, escrever”, Roberto Cardoso de Oliveira afirma que esses três atos epistemológicos são indispensáveis, são atos cognitivos e “esses atos cognitivos [...] assumem um sentido todo particular, de natureza epistêmica, uma vez que são com tais atos que logramos construir nosso saber”. (OLIVEIRA, 2000, p. 18).

A percepção do comportamento e da cultura escolar depende não apenas de sua exteriorização, mas da capacidade do olhar do pesquisador, pois é da característica de todo objeto tentar fugir / escapar dos olhos daquele que o procura. O 'olhar etnográfico’ cerca o objeto, recorta-o, aproxima-se dele para descrevê-lo. Com a descrição do cotidiano escolar torna-se possível identificar as relações sociais que organizam a ordem, neste caso os ritos escolares: posicionamento para ouvir e cantar o Hino Nacional, as reuniões escolares com diretores e supervisores pedagógicos, reuniões do Conselho Escolar, dentre outras.

A etnografia moderna possibilita-nos o acesso à documentação histórica e à percepção do processo de mudança social, uma vez que o cotidiano é composto do presente e do passado. Para essa percepção o pesquisador precisa construir condições de efetivo diálogo (OLIVEIRA, 2000).

A escuta dos dados etnográficos é mais qualificada quando o pesquisador se estrutura a partir das teorias e dos modelos explicativos que o auxiliam na leitura da realidade. Essa 
escuta e leitura são indispensáveis na escrita. O processo de escrita, tanto quanto o momento da análise dos registros dos diários de campo realizados nos momentos de observação, sofreu sínteses e reelaborações com a teoria que estrutura o pensamento do pesquisador.

Quanto ao pensar do pesquisador, vale destacar a vinculação dos ritos com os mitos. Mas como associar mito, rito e o cotidiano escolar? Inicialmente preocupa-nos identificar as implicações existentes entre rito e mito, para demonstrá-las convém trazer à tona o diz Bill Moyers na obra "O poder do mito”, de Joseph Campbell (1990, p. 5): “Mitos são histórias de nossa busca da verdade, de sentido, de significação, através dos tempos”. Outra definição nos diz que o mito é uma narrativa que procura explicar os principais acontecimentos da vida, os fenômenos naturais, as origens do Mundo e do Homem por meio de deuses, semideuses e heróis. O mito é todo relato sério que está em conflito com nossos conhecimentos acerca dos processos naturais (OTTO, 2006)

As definições sobre mito remetem-nos aos processos estruturantes da vida social, a origem da vida, as origens do mundo, as relações do Homem com as divindades, e as implicações desses processos na mente humana é a projeção de construções simbólicas e imaginárias que resulta em práticas sociais. Os mitos, segundo Campbell (1990), ajudam os sujeitos a encontrarem a experiência com a vida. Neste sentido, ele constata o esvaziamento da sociedade americana das narrativas míticas e o consequente empobrecimento dos valores e o aumento da violência urbana, especialmente entre os jovens, como diz Moyers na obra "O poder do mito”: “A sociedade não lhes forneceu ritos por meio dos quais eles se tornariam membros de uma tribo, de uma comunidade”. Por isso, eles construíram “[...] suas próprias gangues, suas próprias iniciações, sua própria moralidade. Estão fazendo o melhor que podem. Mas são perigosos, por que suas leis não são as mesmas da cidade. Eles não foram iniciados na nossa sociedade" (MOYERS apud CAMPBELL 1990, p. 9).

Para Ricouer (1977) e Gusdorf (1953), o mito exerce a função social de cimentar o grupo social, que produz através dos mitos imagens de si, o consenso e a unidade interna. Outra função do mito é estruturar a dominação, como diz Silva (2004, p. 31): “[...] o conhecimento mítico vai tomando formas que respondem às necessidades, sobretudo àquelas das forças dominantes”. Dois mitos contribuem para justificação da ordem estabelecida tanto quanto para emancipação social, o da destinação e o tempo primordial. O primeiro visa repetir o passado no futuro, e o segundo estabelece a garantia da permanência no futuro expresso pelo mito da destinação. Encontram-se nestes mitos o sentido da esperança que alimenta a recuperação do tempo perdido e o messianismo que fortalece a ideia da redenção, em que os grupos alimentam a utopia da chegada de um novo tempo. Portanto, os mitos e os ritos podem ser manipulados pelos grupos sociais para sujeitarem os indivíduos. Na religião, na política, na ciência, no cotidiano e na vida íntima eles são projetados, manipulados para forjarem determinada ordem social.

Os mitos podem servir para dar ordem ao caos social e, ao mesmo tempo, podem ser manipulados em desfavor de grupos sociais, fazendo surgir dominantes e dominados. É neste contexto que situamos este trabalho que busca verificar a existência de ritos no âmbito escolar e suas implicações na cultura da paz.

Como verificar mitos e ritos no cotidiano escolar? Como relacioná-los com as projeções simbólicas e imaginárias que estão no "inconsciente" humano? Como vincular o comportamento infanto-juvenil a esses modelos, quer pela presença ou ausência? 
As teorias sobre mito, ritos e as indicações metodológicas nos levaram às observações diretas (SILVERMAN, 2009), as quais foram realizadas na escola, antes da entrada, durante a acolhida e o intervalo. Também foram feitas várias visitas com o objetivo de fazer as observações diretas das quais resultaram descrições a partir do olhar deste pesquisador e de duas estudantes participantes do projeto.

\section{O cotidiano escolar, as práticas sociais e os ritos}

O estudo no âmbito da escola não pode dispensar o conceito de cultura escolar. Este conceito nos leva às práticas escolares que demonstram as atividades dos seus participantes: gestores, professores, servidores e estudantes. Compreende-se cultura escolar como sendo:

[...] um conjunto de normas que definem conhecimento a ensinar e condutas a inculcar, e um conjunto de práticas que permitem a transmissão desses conhecimentos e a incorporação desses comportamentos; normas e práticas coordenadas a finalidade que podem variar segundo as épocas [...] (JULIA, 2001, p. 10).

Percebe-se por normas a coordenação realizada por regras escritas ou não que formam uma determinada rotina no ambiente escolar. Ou seja, a expectativa por comportamentos que seguem um ritmo específico e atitudes de alunos que produzem a reciprocidade de outros grupos de alunos.

As relações sociais são construídas na base da reciprocidade e do acerto do comportamento de maior frequência, e a probabilidade do acerto reduz o grau de insegurança no campo da sociabilidade. Neste sentido, a sociedade é uma teia na qual as ações são interligadas pela reciprocidade e pelo condicionamento social. Não é distinto no âmbito da escola onde gestores, professores, servidores e estudantes movimentam-se condicionados pelas limitações de classe ou de grupo.

As normas exercem força integradora no interior do grupo, por sua vez as práticas sociais representam a dinâmica do fazer pelos agentes. As práticas manifestam-se autoritárias, conservadoras, progressistas, libertárias, anarquistas, dentre outras, ao mesmo tempo elas podem se apresentar de forma híbrida. Os agentes podem ser conservadores e progressistas, libertários e conservadores, decorrente da natureza dos agentes, de sua ambivalência.

Neste contexto descrever a cultura escolar é também compreendê-la como produtora "[...] de culturas infantis que se desenvolvem nos pátios de recreio e o afastamento que apresentam em relação às culturas familiares” (JULIA, 2001, p. 11).

Convém destacar o caráter reprodutor e/ou transformador da cultura escolar. Inicialmente destacam-se os equívocos produzidos na literatura sociológica, especialmente a sociologia da educação, acerca do pensamento de Pierre Bourdieu. Não são poucos os que assinalam as análises de Bourdieu como reprodutora (SAVIANI, 1999; JULIA, 2001). A constatação de uma realidade que produz mecanismos de inibição da mobilidade social e reivindica a inércia social, fazendo lembrar o sistema feudal, não pode ser confundida como uma postura metodológica.

Para Bourdieu (1996), as categorias de habitus e campo manifestam as relações de força existentes num determinado grupo social e por analogia no espaço social (sociedade). Enquanto a primeira significa o conjunto de disposições duráveis situados na mente e no corpo do indivíduo, estando à disposição e ao alcance do agente para ser modificada ou 
reproduzida. Por sua vez a segunda categoria define os limites de atuação do habitus, sendo compreendida como um campo de forças que põe em disputa grupos concorrenciais, e o êxito de um sobre o outro dependerá da agregação de capitais que os agentes dos grupos possuírem. Nesta perspectiva não há determinação a priori, pois a reprodução social pode ocorrer como resultado da concorrência entre grupos e entre os agentes.

Para Bourdieu a escola tem a destinação das crianças a partir do momento que não é neutra e opta por reproduzir a cultura de determinada classe social. Ao contrário do que pensa Julia (2001) e Bourdieu (2001, 1996) que afirmam que a educação (escola) possui cultura a qual é repassada para seus colaboradores (frequentadores), Forquin (1993, p. 15) afirma:

A educação não transmite jamais a cultura, considerada como um patrimônio simbólico e unitário e imperiosamente coerente. Nem sequer diremos que ela transmite fielmente uma cultura ou culturas, elementos de uma cultura, entre os quais não há forçosamente homogeneidade [...]. Isto significa dizer que a relação entre educação e cultura poderia ser mais bem (sic) compreendida através da metáfora da bricolage [...].

Nesta citação percebe-se, segundo o autor, que a escola não tem capacidade de dar unidade à ideia de cultura, que se apresenta como uma colcha de retalhos no interior da educação. A dinâmica ocorre pelos empréstimos de valores e crenças dos vários sistemas de cultura.

No atual contexto da modernidade, a cultura pensada por Forquin (1992) não se apresenta com tanta homogeneidade. A dinâmica social é complexa, e os vários sistemas tornaram-se heterônimos, ou seja, são complexos de culturas plurais nos quais existem contribuições de vários grupos religiosos, povos, tribos modernas e outros. No ambiente da escola essa complexidade é refletida. A criança é constantemente atravessada por ideias, práticas e valores dos diversos grupos que compõem a sociedade e capta comportamentos e valores distintos do núcleo familiar. É neste contexto que Campbell afirma que muitos jovens produzem seus próprios ritos, muitos dos quais contrariam os objetivos da sociedade.

Mas como são compreendidos os ritos na sociedade moderna? Como os ritos influenciam os jovens e condicionam o espaço da escola?

\section{Ritos modernos na escola}

A fundamentação teórica exposta apresenta-nos o rito como uma manifestação de uma ordem, quer estabelecida ou não. No caso da segunda, tal como descrita por Campbell ao se referir sobre os jovens da sociedade americana, é resultado do abandono desses jovens pela geração adulta que produzem ‘práticas alternativas' àquelas estabelecidas pela sociedade dominante.

Os ritos que se buscaram observar no cotidiano escolar possuem as características indicadas por Segalen (2002, p. 32):

[...] os ritos devem ser considerados sempre como um conjunto de condutas individuais ou coletivas relativamente codificadas, com suporte corporal (verbal, gestual e de postura), caráter repetitivo e forte carga simbólica para atores e testemunhas. [...] o rito se reconhece como um fruto de uma aprendizagem, implicando, por conseguinte, a continuidade das gerações, dos grupos etários ou dos grupos sociais dentro dos quais se produzem. 
Na citação encontram-se pistas de como identificar o rito na escola: 1) conduta individual ou coletiva repetitiva; 2) forte carga simbólica; 3) produto da aprendizagem; 4) visa ser repassado para gerações seguintes. Portanto, o rito expressa valores sociais, culturais e políticos, além da sua transcendência, mesmo que essa não seja partilhada conscientemente.

As observações foram realizadas na escola no turno da manhã. Desde as 6 horas os observadores estavam posicionados na parte externa da escola e seguiam instruções para evitar sua exposição junto aos alunos e afetar a observação. Na análise das descrições foram utilizados os aportes teóricos descritos neste texto. A escolha das descrições seguiu a de uma organização de conteúdo, apesar das descrições serem de observadores distintos tentou-se dar uma cronologia vinculada ao acontecimento do ato.

A descrição abaixo relata o entorno da escola: a comunidade, o cotidiano do amanhecer das pessoas, a condição social e a religiosidade. Apesar de estar localizada numa periferia, percebe-se a presença do Estado: creche, escola e hospital.

É possível ouvir o som e batidas de carteiras sendo arrumadas no interior das salas. A rua movimenta-se com senhoras donas-de-casa que limpam, varrem suas calçadas e a parte do esgoto que fica em frente às suas casas. A volta do quarteirão confirma o tamanho do espaço estatal, toda quadra é composta desta escola e da creche municipal. À medida que o dia se consolida as pessoas vão aparecendo, saem de suas casas, algumas descabeladas, roupas amassadas, umas vão à padaria, outros apenas deslocam-se, aparentemente sem sentido de um lugar para o outro; outros com roupas mais aparentadas vão para a parada de ônibus, são estudantes, trabalhadores e trabalhadoras. Vamos tomar café na padaria, da padaria observamos mães com seus filhos vindo (sic) comprar pães, trabalhadores e trabalhadoras tomando café. Em frente à padaria, em sua casa, uma senhora ouve músicas gospel (observação 1).

A descrição acima situa a posição social dos alunos da escola observada. O cotidiano da comunidade é marcado pelos traços de uma sociedade competitiva, apressada e transcendente. A marca social dessa sociedade é apresentada na descrição acima: a competição, a luta pela sobrevivência, o ritmo acelerado e a falta de sociabilidade coletiva. A descrição seguinte traz à tona os reflexos dessa conformação social no mundo das crianças. O movimento das pessoas e o ritmo natural dos acontecimentos constituem a realidade, como diz Segalen (2002, p. 29), “Os ritos sociais criam uma realidade que, sem eles, nada seria”. As relações sociais são constituídas por atos simbólicos, pois não existem relações sociais sem sentido. Neste contexto toda a comunidade produz símbolos e ritos, e eles expressam o sentido e o significado da comunidade.

\section{O rito da sociedade competitiva}

O processo de estruturação da dominação social operacionaliza-se no substrato da sociedade, especialmente nos pequenos seres humanos. As crianças, através dos processos de interação, a socialização primária e a socialização secundária, incorporam os valores sociais e reproduzem-nos na interação com outras crianças. Na descrição abaixo, percebe-se o cotidiano de disputa entre crianças no espaço da escola.

Depois 06h30min sai de uma casa que está quase em frente à escola uma menina 
vestindo um vestido verde, com uma mochila escolar e passa a rua num movimento diagonal, passa o primeiro portão que dá acesso ao pátio externo da escola, marca o seu lugar e fica, momentos em pé, outra vez sentada. Não demora muito, outra garota de vestido azul sai, talvez da mesma casa ou uma casa próxima, passa a rua, atravessa o primeiro portão e marca o seu lugar, conversa com a menina que veste verde, posiciona-se, conta os passos para a esquerda, dois ou três passos, e espera. O pátio externo é demarcado por alunos buscando seus espaços e por filas equivalendo sala de aula (observação 1).

A demarcação dos espaços no ambiente escolar é uma realidade, e este processo talvez seja a razão da existência de uma cultura escolar entre professores, alunos e servidores. Quanto aos alunos, a escola é um espaço fundamental para sua entrada no mundo dos adultos e é nela que eles forjam seus primeiros passos institucionais: a fila, o tempo de permanência em determinados espaços, respeito à autoridade dos professores, a obrigatoriedade de fazer e deixar de fazer algumas coisas, tais como os exercícios escolares, as avaliações e outras atividades.

A entrada foi aparentemente organizada, a ordem de entrada das filas ficou a critério de uma pessoa, supõe-se ser professora que as recepcionava para o acolhimento no pátio interno da escola (observação 1).

Perto do portão dois meninos procuram brigar com outro menino que também estava brigando com eles, provocam o garoto como se fosse gente adulta, com gírias chamando para a briga como se fosse dois bandidos, procurando com que o menino cedesse às provocações, mas o menino não cede, procura se afastar deles e vai brincar com as outras crianças (observação 2).
O espaço escolar propicia aos alunos, professores e servidores a constituição de identidades e de identificações, por isso é de fundamental importância o debate em torno da sexualidade, do gênero, da homofobia, religião e valorização profissional. Mais do que isso, a faixa etária dos alunos (entre 06 a 12 anos) cria um ambiente de busca pela sexualidade. No contexto da atual sociedade, como diz Bourdieu (1999, p. 17 e 18):

O sistema mítico-ritual desempenha aqui um papel equivalente ao que incumbe ao campo jurídico nas sociedades diferenciadas: na medida em que os princípios de visão e divisão que ele propõe estão objetivamente ajustados às divisões pré-existentes, ele consagra a ordem estabelecida, trazendo-a à existência conhecida e reconhecida, oficial. [...]. A ordem social funciona como uma imensa máquina simbólica que tende a ratificar a dominação masculina sobre a qual se alicerça [...].

Na descrição da observação 2, foi possível constatar que as crianças procuram manifestar sua masculinidade e virilidade, pois são frequentes as disputas, os chutes, os empurrões, os tapas, as corridas, os encontrões uns com os outros e com a parede da escola. Estes acontecimentos não são exclusivos dos meninos, a competição pela visibilidade alcança o mundo das meninas que formam seus grupos e organizam conspirações, tanto contra meninos quanto contra as meninas. Estas condutas representam valores dominantes na sociedade, porém a desordem é a forma de sua manifestação, a violência. O que fazer para organizar a desordem? Não são poucas as iniciativas por parte de professores, gestores e alunos. Uma das atividades institucionais da escola é o acolhimento. 
Ritos institucionais e práticas pedagógicas

O portão é aberto para que as crianças entrem para o pátio interno e se posicionar em filas, uma professora abre um tipo de boas-vindas falando ao microfone, no seu discurso a professora chama a atenção das crianças para o cuidado com os materiais da escola, a falta de materiais da escola por conta do descuidado com os mesmos. Começam a cantar o hino de Teresina sob o olhar atento dos pais que ficam no pátio externo esperando que seus filhos entrem para a sala em companhia de suas professoras, e só depois que os alunos entram para as salas é que as mães ou responsáveis vão embora (observação 03).

A desordem ameaça a segurança da previsibilidade e, no que se refere ao ambiente escolar, a imprevisibilidade tem se tornado a regra. O retorno à ordem requer ações, uma delas é o acolhimento. O acolhimento acontece após a entrada dos alunos na escola e antes da entrada de alunos e professores na sala de aula. Durante o acolhimento são lembradas as regras da escola, a forma da boa convivência, os modelos exemplares de alunos e tantos outros ‘sermões'. Contudo, a eficácia destas ações é questionável, uma vez que o cotidiano da escola é repleto de transgressão, de incivilidade, de bullying e de atos de violência física.

\section{Conclusões preliminares}

O trabalho fez a descrição de ritos existentes no âmbito da escola, porém os ritos não possuem apenas a função de reforço à ordem estabelecida. Manifestações de comportamentos individuais e coletivos associados à competitividade, à masculinidade, aos conflitos, às identificações de gênero e sexuais acontecidos fora do controle social geram descontrole dos processos de interação social.

Os ritos funcionam como um termômetro do grau de coesão da sociedade. A percepção da existência de ritos na escola que foram criados pela lógica dos jovens pode significar a superação da sociedade tradicional e o amanhecer de uma nova sociedade. Contudo, os valores desses ritos precisam ser observados para evitar a projeção de uma sociedade sem projetos emancipatórios e solidários.

No caso da escola, a observação demonstrou que as crianças de forma inconsciente retratam ações de uma sociedade competitiva e individualista, ao mesmo tempo em que ritualizam valores de mitos que simbolizam uma sociedade que se projeta na crença de uma sociedade melhor.

O cenário da escola vincula mitos, ritos e Ritos a uma estrutura simbólica preconizada no tempo primevo das sociedades humanas, antes mesmo do homo sapiens sapiens demens.

Os sujeitos da escola precisam identificar os momentos em que Ritos se organizam, embora muitos deles não contribuam para a formação de uma cultura de paz, mas buscam alternativas no espaço da competitividade e individualidade, e que são, muitas vezes, implicadores de violência.

\section{Referências}

BOAS, F. A formação da antropologia americana, 1883-1911. Rio de Janeiro: Contraponto, 2004.

BOURDIEU, P. Meditações pascalianas. Rio de Janeiro: Bertrand Brasil, 2001.

A dominação masculina. Rio de Janeiro: Bertrand Brasil, 1999. 
- As razões práticas. Campinas: Papirus, 1996.

CAMPBELL, J. O poder do mito. (Org. Betty Sue Flowers); Tradução Carlos Felipe Moisés. São Paulo: Palas Atenas, 1990.

As máscaras de Deus. Tradução Carmem Fischer. São Paulo: Palas Athenas, 1992.

ELIADE, M. Mito e realidade. $4^{\mathrm{a}}$ ed. São Paulo: Ed. Perspectiva, 1994.

FORQUIN, J. C. Escola e cultura: a sociologia do conhecimento escolar. Porto Alegre: Artes Médicas, 1993.

Saberes escolares, imperativos didáticos e dinâmicas sociais. Teoria \& Educação, Porto Alegre, n.5, p. 28-49, 1992.

GEERTZ, C. Nova luz sobre a antropologia. Rio de Janeiro: Jorge Zahar, 2001.

GIRARD, R. A violência e o sagrado. São Paulo: Ed. Universidade Estadual Paulista, 1990.

GOMES, M. P. Antropologia: ciência do homem, filosofia da cultura. São Paulo: Contexto. 2009.

GUSDORF, G. Mythe et Metaphysique: introduction à la philosophie. Paris, Flamarion, 1953.

JULIA, D. A cultura escolar como objeto histórico. Revista Brasileira de História da Educação. Campinas, n. 1, p.9-44, 2001.

LAPLANTINE, F. Aprender antropologia. São Paulo: Brasiliense, 1999.

OLIVEIRA, R.C. Otrabalho doAntropólogo. São Paulo: Editora UNESP, 2000.

OTTO, W. E. T. O espírito da religião dos gregos antigos. Tradução Ordep T. Serra. São Paulo: Odysseus, 2006.
RICOEUR, P. Interpretações e ideologias. Rio de Janeiro: Francisco Alves, 1997.

SAVIANI, D. Escola e democracia. 32 ed. Campinas: Autores Associados, 1999.

SEGALEN, M. Ritos e ritos contemporâneos. Rio de Janeiro: Editora FGV, 2002.

SILVA, J. I. da. O conhecimento mítico e as estruturas da produção social: uma contribuição para a produção do conhecimento na educação. In: SCRPTORI, C. C. (Org.). Universidade e conhecimento: desafios e perspectivas no âmbito da docência, pesquisa e extensão. Campinas: Mercado das Letras, 2004.

SILVERMAN, D. Interpretação dos dados qualitativos: métodos para análise de entrevista, textos e interações. Porto Alegre: Artmed, 2009.

VAN GENNEP, A. Os ritos de passagem. Petrópolis: Vozes, 1978. 